\title{
Hearing Loss in Infants with Microcephaly and Evidence of Congenital Zika Virus Infection — Brazil, November 2015-May 2016
}

\author{
Mariana C. Leal, $\mathrm{PhD}^{1,2}$; Lilian F. Muniz, $\mathrm{PhD}^{2}$; Tamires S.A. Ferreira, $\mathrm{MD}^{1}$; Cristiane M. Santos, $\mathrm{MD}^{1}$; Luciana C. Almeida ${ }^{2}$; \\ Vanessa Van Der Linden, MD ${ }^{3,4}$; Regina C.F. Ramos, $\mathrm{MD}^{5}$; Laura C. Rodrigues, $\mathrm{PhD}^{5}$; Silvio S. Caldas Neto, $\mathrm{PhD}^{2}$
}

On August 30, 2016, this report was posted as an MMWR Early Release on the MMWR website (http://www.cdc.gov/mmwr).

Congenital infection with Zika virus causes microcephaly and other brain abnormalities (1). Hearing loss associated with other congenital viral infections is well described; however, little is known about hearing loss in infants with congenital Zika virus infection. A retrospective assessment of a series of 70 infants aged $0-10$ months with microcephaly and laboratory evidence of Zika virus infection was conducted by the Hospital Agamenon Magalhães in Brazil and partners. The infants were enrolled during November 2015-May 2016 and had screening and diagnostic hearing tests. Five (7\%) infants had sensorineural hearing loss, all of whom had severe microcephaly; however, one child was tested after receiving treatment with an ototoxic antibiotic. If this child is excluded, the prevalence of sensorineural hearing loss was 5.8\% (four of 69), which is similar to that seen in association with other congenital viral infections. Additional information is needed to understand the prevalence and spectrum of hearing loss in children with congenital Zika virus infection; all infants born to women with evidence of Zika virus infection during pregnancy should have their hearing tested, including infants who appear normal at birth.

The most well-described feature of congenital Zika syndrome is microcephaly $(2,3)$. Clinical aspects appear to be predominantly neurologic, with neuroimaging showing calcifications between cortical and subcortical zones, cortical development errors, and pachygyria/agyria (2-4). In addition to the neurologic manifestations, ophthalmic (5) and orthopedic (1) lesions have been described as a component of the syndrome. A single study in Brazil investigated auditory function among 23 neonates with microcephaly and presumed congenital Zika virus infection, using otoacoustic emissions testing without a confirmatory examination, and found $9 \%$ with auditory deficits (4). In all of the studies described, Zika virus infection was a diagnosis of exclusion because, at the time, specific testing for Zika virus was not readily available. Hearing loss is a well established feature of other congenital infections, including cytomegalovirus (CMV), rubella, toxoplasmosis, herpes simplex, and syphilis. In these syndromes, the hearing loss is sensorineural, usually bilateral, and severe or profound; it is often undetectable at birth, and sometimes it is progressive or fluctuating $(6,7)$.
During November 2015-May 2016, as part of the protocol for evaluation of children who were born with microcephaly during the Zika virus disease epidemic, 150 children were referred to Hospital Agamenon Magalhães, a reference center for diagnosis of hearing loss and hearing rehabilitation in Pernambuco, Brazil; the 23 children previously evaluated in Pernambuco (4) were not part of this cohort. This report is a retrospective analysis of hearing assessments in 70 infants aged $0-10$ months with microcephaly and laboratory evidence of Zika virus infection evaluated during that time. Zika virus-associated microcephaly was defined as head circumference $\leq 32 \mathrm{~cm}$ for term newborns (gestational age at birth 37 weeks to 41 weeks and 6 days), or at least two standard deviations below the mean for gestational age and sex using the Fenton curve for preterm newborns (8), with the characteristic radiologic findings from cranial computerized tomography or magnetic resonance imaging, and laboratory confirmation of Zika virus by a positive Zika virus-specific immunoglobulin $\mathrm{M}(\mathrm{IgM})$ capture enzyme-linked immunosorbent assay (ELISA) performed on cerebrospinal fluid (9).* Other infectious causes of congenital sensorineural hearing loss, including CMV, toxoplasmosis, herpes simplex, and syphilis, were excluded by serologic testing of infants and their mothers. Information was collected concerning the presence and timing of rash during pregnancy and on maternal or perinatal risk factors for congenital hearing loss, such as alcohol consumption, familial hearing loss, ototoxic drug exposure, birth trauma, and postnatal infections. The degree of microcephaly was evaluated, with severe microcephaly defined as head circumference at birth of at least three standard deviations below the mean for gestational age and sex.

Auditory evaluation was carried out by screening and diagnostic tests as recommended by the American Academy of Pediatrics' Joint Committee on Infant Hearing (10). The screening test consisted of measurement of the short latency auditory brainstem response (ABR) to click stimuli, and was considered to be normal when wave $\mathrm{V}$ (the fifth and most prominent and consistent wave) was identified in two consecutive averaged waveforms at 35 decibels normal hearing level ( $\mathrm{dB} \mathrm{nHL}$ ). If the first screening test was not normal, it was repeated approximately 1 month later. If the second test also indicated hearing loss, a diagnostic confirmatory

\footnotetext{
* Used in accordance with the CDC emergency use authorization protocol.
} 
frequency-specific $A B R$ was conducted, in which the stimuli were tone bursts at frequencies of 500 and 2,000 Hz. The diagnosis of hearing loss was confirmed if hearing thresholds exceeded $25 \mathrm{~dB}$ nHL. No behavioral auditory testing was performed. Conductive hearing loss was not considered to be related to Zika virus infection because the hearing impairment caused by congenital viral infections is sensorineural. All children considered normal on hearing evaluation will be regularly assessed for evidence of late-onset hearing impairment. Associations between sensorineural hearing loss and presence of maternal rash during pregnancy, timing of maternal rash during pregnancy, and severe microcephaly were analyzed using contingency tables and tested using Fisher's exact test, with statistical significance defined as $\mathrm{p}<0.05$. Although all investigations were carried out as part of routine clinical care, and human subjects review was not required, the protocol was submitted for ethical review and approved by Hospital Agamenon Magalhães.

The mean age at the first auditory testing was $114 \pm$ 59.1 days (range $=16-315$ days, median $=97$ days). Among all 70 infants, $16(22.8 \%)$ failed the first screening test in at least one ear; among these, eight failed the repeat test and were evaluated by frequency-specific ABR. The diagnosis of hearing impairment was confirmed by $A B R$ in seven (10\%) children, including two with conductive hearing loss and five with sensorineural hearing loss. Sensorineural hearing loss was bilateral in three children and unilateral in two. One child with bilateral profound sensorineural hearing loss had been treated for sepsis with intravenous amikacin, an antibiotic with known ototoxicity, before the first test. A second child with bilateral profound sensorineural hearing loss had a twin brother with normal head circumference and cerebrospinal fluid negative for Zika-specific IgM. A third infant with sensorineural hearing loss had moderate impairment on the left and profound impairment on the right. One of the two infants with unilateral sensorineural hearing loss had mild impairment, and the other had profound impairment.

Information on presence of rash during pregnancy was obtained from 63 mothers, 54 (86\%) of whom reported a rash during pregnancy (Table). Among these 54 mothers, $41(76 \%)$ experienced the rash during the first trimester. The mothers of four infants with confirmed sensorineural hearing loss, including the one infant treated with amikacin, reported having had a rash during the first 3 months of pregnancy; the mother of the fifth infant with confirmed sensorineural hearing loss reported having had a rash in the fourth month of pregnancy. Timing of maternal rash during pregnancy did not differ between infants with and without sensorineural hearing loss $(p=0.64)$. Information needed to determine the degree
TABLE. Number of infants with microcephaly and laboratory evidence of congenital Zika virus infection ( $\mathrm{N}=70)$, by hearing test status, and selected characteristics - Brazil, November 2015-May 2016

\begin{tabular}{|c|c|c|}
\hline $\begin{array}{l}\text { Characteristic (number with } \\
\text { information available) }\end{array}$ & $\begin{array}{l}\text { No hearing loss } \\
\text { or conductive } \\
\text { hearing loss } \\
(n=65) \text { No. }(\%)\end{array}$ & $\begin{array}{c}\text { Sensorineural } \\
\text { hearing loss } \\
(n=5) \text { No. }(\%)\end{array}$ \\
\hline $\begin{array}{l}\text { Gestational age at birth } \\
37-41 \text { weeks (term) } \\
<37 \text { weeks (preterm) } \\
\geq 42 \text { weeks (postterm) }\end{array}$ & $\begin{array}{r}(n=59) \\
50(85) \\
8(14) \\
1(2)\end{array}$ & $\begin{array}{l}(n=5) \\
5(100) \\
0(-) \\
0(-)\end{array}$ \\
\hline $\begin{array}{l}\text { Self-reported rash during pregnancy } \\
\text { Yes } \\
\text { No }\end{array}$ & $\begin{array}{r}(n=58) \\
49(84) \\
9(16)\end{array}$ & $\begin{array}{r}(n=5) \\
5(100) \\
0(-)\end{array}$ \\
\hline $\begin{array}{l}\text { Timing of rash during pregnancy } \\
\text { First trimester } \\
\text { Second trimester } \\
\text { Third trimester }\end{array}$ & $\begin{array}{r}(\mathrm{n}=49) \\
37(76) \\
10(20) \\
2(4)\end{array}$ & $\begin{array}{r}(n=5) \\
4(80) \\
1(20) \\
0(-)\end{array}$ \\
\hline $\begin{array}{l}\text { Infant sex } \\
\text { Male } \\
\text { Female }\end{array}$ & $\begin{array}{r}(n=65) \\
36(55) \\
29(45)\end{array}$ & $\begin{array}{r}(n=5) \\
3(60) \\
2(40)\end{array}$ \\
\hline $\begin{array}{l}\text { Degree of microcephaly } \\
\text { Severe ( }>3 \text { SD below mean for } \\
\text { gestational age) }\end{array}$ & $\begin{array}{r}(n=60) \\
39(65)\end{array}$ & $\begin{array}{l}(n=5) \\
4(100)\end{array}$ \\
\hline $\begin{array}{l}\text { Other ( } \leq 3 \text { SD below mean for } \\
\text { gestational age) }\end{array}$ & $21(35)$ & $0(-)$ \\
\hline Age at testing (days) & $(n=70)$ & $(n=5)$ \\
\hline Mean & 114 & 105 \\
\hline Median & 98 & 60 \\
\hline SD & 59 & 57 \\
\hline Range & $16-315$ & $36-171$ \\
\hline
\end{tabular}

Abbreviation: $\mathrm{SD}=$ standard deviation.

of microcephaly was available for 65 (93\%) infants, among whom 44 (68\%) had severe microcephaly; all five children with sensorineural hearing loss were in this group; however, no significant association was detected between the presence of sensorineural hearing loss and severe microcephaly $(\mathrm{p}=0.55)$.

\section{Discussion}

In this report of complete auditory function evaluation in a series of 70 children with microcephaly and laboratory evidence of congenital Zika virus infection, five (7.1\%) infants had sensorineural hearing loss. The hearing loss varied in severity and laterality, which has been reported in hearing loss associated with other congenital infections $(6,7)$. If the one infant with bilateral profound sensorineural hearing loss who had been treated with amikacin (a known ototoxic antibiotic) before the hearing testing is excluded, the proportion of infants with sensorineural hearing loss was $5.8 \%$ (four of 69 ). This proportion, although lower than the $9 \%$ reported from a small sample of newborns with microcephaly associated with presumed Zika-virus infection tested by otoacoustic emissions (4), is within the range $(6 \%-65 \%)$ reported for other congenital viral infections $(6,7)$. In the majority of cases of hearing loss associated with congenital viral infection, the damage to the auditory system is within the cochlea ( 7$)$. It is likely that 


\section{Summary}

What is already known about this topic?

Congenital Zika virus infection is characterized by microcephaly and other abnormalities of the brain and eye; orthopedic lesions have also been documented. While the full clinical spectrum of the syndrome is not yet known, the neurologic damage and corresponding radiologic brain imaging have been well described. Other congenital infections can cause hearing loss, which is diagnosed at birth or during later follow-up; however, few data exist regarding hearing loss associated with confirmed congenital Zika virus infection.

What is added by this study?

Congenital infection with Zika virus appears to be associated with sensorineural hearing loss. Among 70 children with microcephaly and laboratory evidence of congenital Zika virus infection, four of 69 (5.8\%) were found to have sensorineural hearing loss without other potential cause.

What are the implications for public health practice?

Congenital infection with Zika virus should be considered a risk factor for hearing loss. Children with evidence of congenital Zika virus infection who have normal initial screening tests should receive regular follow-up, because onset of hearing loss associated with other congenital viral infections can be delayed and the loss can be progressive.

similar lesions account for the hearing deficit in children with congenital Zika virus infection, although histologic studies are needed to confirm this. However, a concomitant central origin cannot be discounted, and behavioral auditory evaluation might provide additional information.

The findings in this report are subject to at least two limitations. First, auditory behavioral tests, in which an infant's responses (e.g., quieting, eye-widening, or startle) to various calibrated sounds are recorded, and which can complement the hearing evaluation and provide information about processing of auditory signals, were not used. Second, this series includes only children with microcephaly. It is possible that the full spectrum of congenital Zika virus infection includes children without microcephaly, but with auditory deficits, as occurs in congenital rubella and CMV infections, in which children born with no apparent structural anomaly can be found to have hearing loss at birth or later in life.

Although no statistically significant associations of hearing loss with timing of rash during pregnancy and degree of microcephaly were detected, sensorineural auditory impairment occurred predominantly in infants whose mothers had a rash illness during the first trimester of pregnancy, and all the infants with sensorineural hearing loss had severe microcephaly. Therefore, severe microcephaly in infants with evidence of congenital Zika virus infection should be considered a risk factor for auditory impairment.
The prevalence of progressive hearing loss associated with congenital Zika virus infection is not known. To elucidate the full spectrum of hearing loss in infants with congenital Zika virus infection, testing and follow-up of all children born to women who had Zika virus infection during pregnancy, including infants with no apparent anomalies at birth, is needed. Sensorineural hearing loss should be considered part of the spectrum of clinical findings associated with congenital Zika virus infection, and congenital Zika virus infection should be considered a risk factor for hearing loss in auditory screening programs. Children with evidence of congenital Zika virus infection who have normal initial screening tests should receive regular follow-up, because onset of hearing loss could be delayed and the loss could be progressive.

\section{Acknowledgments}

Marli Tenório, MD, Ernesto Marques, MD, Virology and Experimental Therapy Department, Oswaldo Cruz Foundation, Pernambuco, Brazil.

\footnotetext{
${ }^{1}$ Hospital Agamenon Magalhães; ${ }^{2}$ Federal University of Pernambuco; ${ }^{3}$ Association for Assistance of Disabled Children; ${ }^{4}$ Oswaldo Cruz University Hospital; 5 London School of Hygiene and Tropical Medicine.

Corresponding author: Mariana C. Leal, marianacleal@hotmail.com.
}

\section{References}

1. Rasmussen SA, Jamieson DJ, Honein MA, Petersen LR. Zika virus and birth defects—reviewing the evidence for causality. N Engl J Med 2016;374:1981-7.

2. Schuler-Faccini L, Ribeiro EM, Feitosa IML, et al. Possible association between Zika virus infection and microcephaly. MMWR Morb Mortal Wkly Rep 2016;65:59-62. http://dx.doi.org/10.15585/mmwr.mm6503e2

3. Aragão MFV, Van der Linden V, Brainer-Lima AM, et al. Clinical features and neuroimaging (CT and MRI) findings in presumed Zika virus related congenital infection and microcephaly: retrospective case series study. BMJ 2016;353:i1901. http://www.bmj.com/content/353/bmj.i1901

4. Microcephaly Epidemic Group. Microcephaly in infants, Pernambuco State, Brazil, 2015. Emerg Infect Dis 2016;22:1090-3. http://wwwnc. cdc.gov/eid/article/22/6/16-0062_article

5. Ventura CV, Maia M, Bravo Filho V, Gois AL, Belfort R Jr. Zika virus in Brazil and macular atrophy in a child with microcephaly. Lancet 2016;387:228. http://www.thelancet.com/journals/lancet/article/ PIIS0140-6736(16)00006-4/abstract

6. Goderis J, De Leenheer E, Smets K, Hoecke HV, Keymeulen A, Dhoogeet I. Hearing loss and congenital CMV infection: a systematic review. Pediatrics 2014;134:972-82. http://pediatrics.aappublications. org/content/134/5/972

7. Cohen BE, Durstenfeld A, Roehm PC. Viral causes of hearing loss: a review for hearing health professionals. Trends Hear 2014;18. pii: 2331216514541361

8. Brazilian Ministry of Health. Protocol for monitoring and response to microcephaly occurrence relating to ZikaV infection [Portuguese]. http:// www.combateaedes.saude.gov.br/images/sala-de-situacao/MicrocefaliaProtocolo-de-vigilancia-e-resposta-10mar2016-18h.pdf

9. Cordeiro MT, Pena LJ, Brito CA, Gil LH, Marques ET. Positive IgM for Zika virus in the cerebrospinal fluid of 30 neonates with microcephaly in Brazil. Lancet 2016;387:1811-2.

10. American Academy of Pediatrics, Joint Committee on Infant Hearing. Year 2007 position statement: principles and guidelines for early hearing detection and intervention programs. Pediatrics 2007;120:898-921. 